\title{
ASSESSMENT OF KNOWLEDGE AND PRACTICE TOWARD DISPOSAL OF EXPIRED DRUGS AMONG MEDICAL PROFESSIONALS IN CHENNAI - A CROSS-SECTIONAL PROSPECTIVE STUDY
}

\author{
UMAMAGESWARI A*, GURU SCINDIA MV, PRIESTLY VIVEKKUMAR S, GEETHA R
}

Department of Pharmacology, Tagore Medical College and Hospital, Chennai, Tamil Nadu, India. Email: leeuma6@gmail.com

Received: 22 July 2017, Revised and Accepted: 13 September 2017

\section{ABSTRACT}

Objective: Proper disposal of expired drugs can avoid drug abuse, drug diversion, environmental contamination, and accidental poisoning by children and animals. Our study was aimed to assess the knowledge and practice toward disposal of expired drugs among medical professionals.

Methods: After obtaining verbal consent, a self-administered pretested questionnaire was given to tutors, junior resident, senior resident, assistant professors, associate professors, and professors of Tagore Medical and Dental College and Hospital. The questionnaire has two parts; part one includes demographic details of the study participants, and part two comprises questions, regarding their awareness, knowledge, and practice toward disposal of expired drugs. Data were described as a percentage and analyzed using Sigma Graphpad prism version-5 and Microsoft Excel 2007.

Results: A total of 156 medical professionals participated in the study. Among them, 85 were males and 71 were females, whereas 123 (78.8\%) were medical and $33(21.2 \%)$ were dental faculties. It was observed that $74.3 \%$ of respondents check the expiry date of the drug always and $62.2 \%$ said the drug loses its therapeutic effect after the expiry date. Analyzing the method to dispose the expired drugs, $77.6 \%$ throw in their household dustbins, $2.6 \%$ flush in toilets, $19.2 \%$ return to the pharmacist, and $4.5 \%$ bury. One-fourth of the medical professionals not aware about environmental hazards due to improper disposal and also believe they do not cause any harm. $64 \%$ of preferred pharmacist would be the appropriate person to inform about proper disposal of drugs.

Conclusion: This study shows lacunae in the knowledge and practice about proper disposal of expired drugs and recommends discussion regarding improper disposal and its consequences in various health programs.

Keywords: Expiry date, Disposal methods, Medical professionals, Shelf life.

(c) 2017 The Authors. Published by Innovare Academic Sciences Pvt Ltd. This is an open access article under the CC BY license (http://creativecommons. org/licenses/by/4. 0/) DOI: http://dx.doi.org/10.22159/ajpcr.2017.v10i12.21529

\section{INTRODUCTION}

The expiry date is the actual date placed on the label where the time during which a particular batch of drug product is expected to remain with the approved shelf life specifications if stored under defined conditions beyond its use should not be allowed [1]. Shelf life of a drug is defined as the time interval where it remains physically, chemically, and/or biologically stable ( $>90 \%$ of potency) as well as safe and effective for human consumption if stored under the label specified conditions, and it is in the original container closure system. Even after the expiry date, most of the drugs remain in stable condition for at least 5 years and sometimes much longer [2]. Due to certain legal compulsions and liability concerns, the drug manufacturers do not entertain such use of expired drugs. In case of emergency situation, regulatory authorities allow reuse of expired pharmaceutical products for human use after thorough analysis and revalidation.

The WHO recommends various disposal methods [3] such as incineration, waste encapsulation, inertization, landfill, sewer, fastflowing watercourse, burning in open containers and return to donor or manufacturer, and transfrontier transfer for disposal. In India, to dispose pharmaceutical waste by the local pollution, control body at an approved solid waste disposal site costs about Rs.15-25 per Kg. The total cost of such disposal works out to about $0.5-2 \%$ of the total sales [1]. The need of the hour is to minimize the expenses incurred for disposal of waste pharmaceuticals which can be achieved by sorting various pharmaceutical products and following the disposal methods accordingly. Disposal of expired drugs not only involves huge cost but also may be hazardous if it leads to contamination of land, air, water sources, and aquatic lives which is recycled affecting human beings, animals, and vegetation in one or the other form.
As such, expired pharmaceuticals do not pose a serious threat to public health or to the environment when handled in the proper manner. Improper drug disposal causes various consequences such as accidental consumption of expired drugs by children and animals, stealing of discarded drugs from stockpile or during sorting can be diverted to the market for resale or misuse [4]. On consumption of outdated drugs such as nitroglycerine, insulin, and liquid, antibiotics may develop serious adverse drug reaction, and most of the expired drugs due to improper storage condition may lose their efficacy [5]. Burning outdated pharmaceuticals at low temperatures or in open containers may result in release of toxic pollutants into the air. Disposal of non-biodegradable antibiotics, anticancer agents, and disinfectants into the sewage system may kill bacteria necessary for the treatment of sewage.

As the topic is an emerging global issue, the present study aims to assess the knowledge and practice toward disposal of expired drugs among medical professionals in Chennai. On introducing the medical professionals to various questions, the study would enlighten the thinking toward safe disposal of expired drugs.

\section{METHODS}

The study was a cross-sectional, questionnaire-based conducted in Tagore Medical College and Hospital, Chennai, Tamil Nadu. The study participants were the tutors, junior resident, senior resident, assistant professors, associate professors, and professors of Tagore Medical and Dental College and Hospital. After obtaining the Institutional Ethics Committee approval, the study was commenced. The importance of the study was explained to the faculties. After gaining their verbal consent, a self-administered pre-tested questionnaire was given to them and collected back. A literature review was done before framing the 
questionnaire and was validated by senior professionals. Questionnaire was comprised of two parts. Part one includes demographic details of the study participants such as gender, age, dental or medical profession, department, and designation. Part two comprises of seven questions, regarding their awareness, knowledge, and practice toward disposal of expired drugs. The questions were formulated with multiple choices, where the faculties were given the choice of expressing more than one option for that particular question. Completely filled questionnaires were taken for data analysis. Incompletely filled questionnaire was excluded from the study. Data were described as a percentage and analyzed using Sigma Graphpad prism version-5 and Microsoft Excel 2007.

\section{RESULTS}

A total of 156 completely filled questionnaires were collected back from the medical professionals. Among them, 85 (54.5\%) were males and $71(45.5 \%)$ were females. $102(65.4 \%)$ were in the age group of $20-40$ years, $45(28.8 \%)$ and $9(5.8 \%)$ in the age group between 40 and 60 years and more than 60 years, respectively. Regarding profession, 123 (78.8\%) were medical faculties, and 33 (21.2\%) were dental faculties. Among them, 92 (59\%) belongs to various clinical departments, 64 (41\%) belongs to pre- and para-clinical departments. Based on their designation, $63(40.4 \%)$ were tutors or junior resident or senior residents, 46 (29.5\%) were assistant professors, 29 (18.6\%) were associate professors, and $18(11.5 \%)$ were professors (Table 1 and Fig. 1).

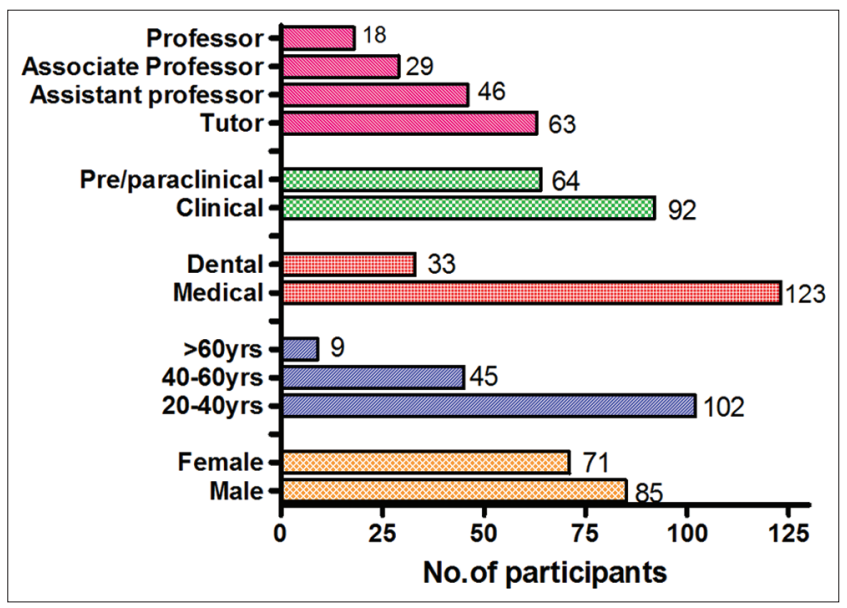

Fig. 1: Demographic details of the medical professionals $(n=156)$

Table 1: Demographic details of the medical professionals $(n=156)$

\begin{tabular}{ll}
\hline Variables/parameters & Number of participants (\%) \\
\hline Gender & \\
Male & $85(54.5)$ \\
Female & $71(45.5)$ \\
Age & $102(65.4)$ \\
$20-40$ & $45(28.8)$ \\
$40-60$ & $9(5.8)$ \\
$>60$ & \\
Profession & $123(78.8)$ \\
Medical & $33(21.2)$ \\
Dental & \\
Department & $92(59.0)$ \\
Clinical & $64(41.0)$ \\
Pre-/Para-clinical & \\
Designation & $63(40.4)$ \\
Tutor/JR/SR & $46(29.5)$ \\
Assistant Professor & $29(18.6)$ \\
Associate Professor & $18(11.5)$ \\
Professor &
\end{tabular}

It was observed that $116(74.3 \%)$ respondents check expiry date of the drug always while purchasing, whereas 31 (19.9\%) do occasionally and $9(5.8 \%)$ never look for it (Fig. 2), regarding the nature of the drug beyond expiry date, it was observed that $57(36.5 \%)$ respondents said that it becomes toxic, 9 (5.8\%) opted that it remains same, 97 (62.2\%) said that it loses its therapeutic effect, and 7 (4.5\%) said that depending on the drug it might become toxic or loses its therapeutic effect. When observed about the cause for the availability of expired drugs in the house, $98(62.8 \%)$ respondents said self discontinuation of drugs, 62 $(39.7 \%)$ due to purchase of over the counter drugs, $11(7.1 \%)$ due to irrational prescription, whereas $13(8.3 \%)$ quoted two options, i.e., selfdiscontinuation and purchase of over the counter drugs and $2(1.3 \%)$ opted self-discontinuation and irrational prescription (Table 2).

On observing the method to dispose the expired drugs, 121 (77.6\%) throw in their household dustbins, $4(2.6 \%)$ flush them in toilets, $30(19.2 \%)$ return to the pharmacist, $7(4.5 \%)$ bury, and $5(3.2 \%)$ preferred other modes of disposal. 3 (1.9\%) preferred both throwing and flushing, whereas 8 (5.2\%) preferred throwing and returning the expired drugs (Fig. 3). When evaluating the awareness about environmental hazards due to improper disposal, 117 (75\%) aware of the consequences, 17 (10.9\%) were not aware, and 22 (14.1\%) opted do not cause any harm (Fig. 4).

Regarding the appropriate person to inform about proper disposal, it was observed that $83(53.2 \%)$ opted doctors, 17 (10.9\%) nurses, 100 (64.1) pharmacist, 6 (3.8\%) other paramedical staffs, and $19(12.2 \%)$ government officials. 69 (44.2\%) preferred a combination of 2-4 options (Fig. 5). On assessing the practice of educating the patients about disposal methods, 36 (23.1\%) have suggested their patients,

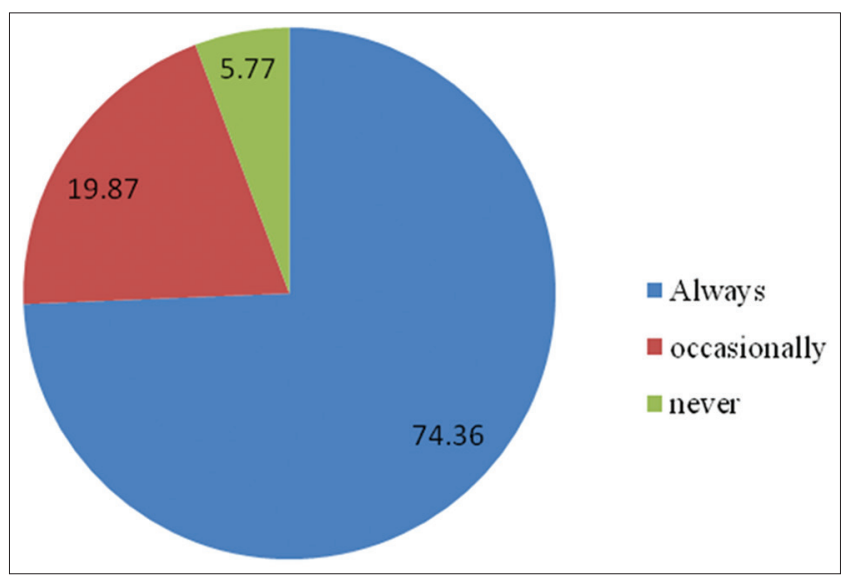

Fig. 2: Do you check expiry date of the drug while purchasing expressed in percentage $(\%)$

Table 2: Knowledge regarding expired drugs

\begin{tabular}{ll}
\hline Questions & $\begin{array}{l}\text { Number of } \\
\text { respondents (\%) }\end{array}$ \\
\hline $\begin{array}{l}\text { What will be nature of drugs beyond expiry } \\
\text { date? }\end{array}$ \\
A. Toxic & $57(36.5)$ \\
B. Remains same & $9(5.8)$ \\
C. Loses its effect & $97(62.2)$ \\
Both (A) and (C) & $7(4.5)$ \\
What may be the cause for the availability of & \\
expired drugs in the house? & \\
A. Self-discontinuation & $98(62.8)$ \\
B. Over the counter drugs & $62(39.7)$ \\
C. Irrational prescription & $11(7.1)$ \\
Both (A) and (B) & $13(8.3)$ \\
Both (A) and (C) & $2(1.3)$ \\
\hline
\end{tabular}




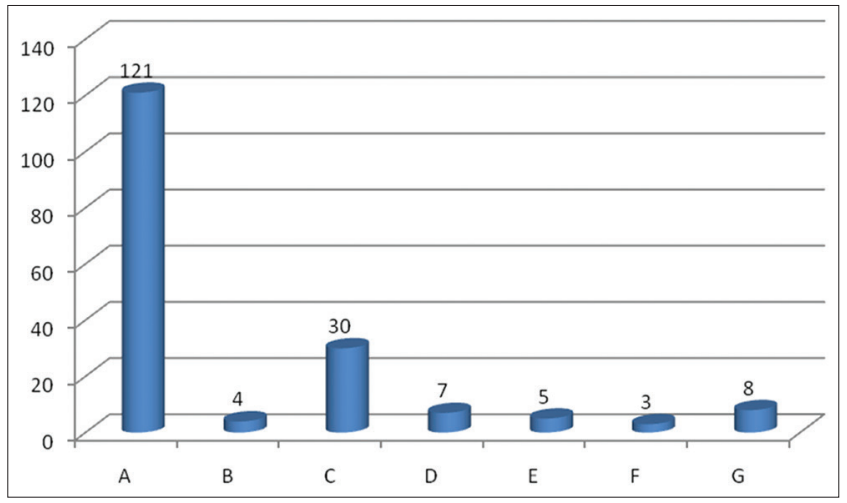

Fig. 3: Which method are you following to dispose the expired drugs, expressed in a number of respondents. A - Throwing (77.6\%), B - flushing (2.6\%), C - returning to the Pharmacist (19.2\%), D - burying (4.5\%), E - others (3.2\%), F - throwing + flushing $(1.9 \%)$, G - throwing + returning to pharmacist $(5.2 \%)$

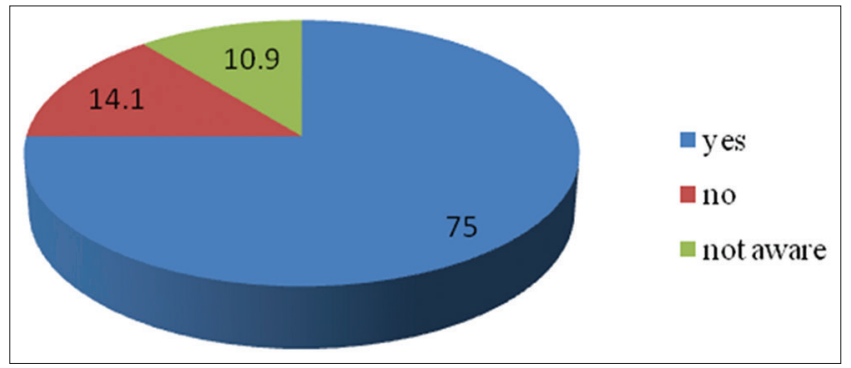

Fig. 4: Do improper disposal cause environmental hazards, expressed in percentage (\%)

while $78(50 \%)$ have not done. Since non-practising professionals were also included, 42 (26.9\%) preferred not applicable (Fig. 6).

\section{DISCUSSION}

The expiry date is the time when a pharmaceutical product is no longer within an acceptable condition to be considered effective, and it depends on a fixed time after the product manufacture, dispensing and finally opening of the drug container [6]. Once the drug container is opened, the expiry date can be drastically shortened. Various other factors such as contact with water, temperature, air, or light can also affect the expiry date. Shelf life of drugs depends on degradation of the active drug and degree of contamination. Hence, basic storage guidelines should be followed while handling the drugs, irrespective of their expiry date.

In this study, the majority (74.3\%) of the medical professionals always look at the expiry date before purchasing. According to the Expiry Date Guidelines for Medication, wording of expiry date on the drug package should be interpreted properly. Regarding about the nature of the drugs beyond the expiry date, most of the drugs merely lose their potency not toxic except for tetracycline. Few reports show the association of renal tubular dysfunction and consumption of expired tetracyclines [7,8]. At present, stability and the formulation have been improved to overcome the toxicity $[9,10]$. In our study, self-discontinuation followed by over the counter drugs such as antibiotics, antidepressants, antacids, and laxatives [11] are the reasons for piling up of expired drugs which was in accordance with the previous studies [12]. There is a need to enforce laws to discourage dispensing the medicines without prescriptions [13]. The other reasons for accumulation of drugs which later reach the expiry date were side effect intolerance, dose escalation, or reduction [14]. According to Jawahir et al., unused or leftover medications should not be kept at home for the future use [15]. About method of disposal of expired drugs in the present study, almost $78 \%$

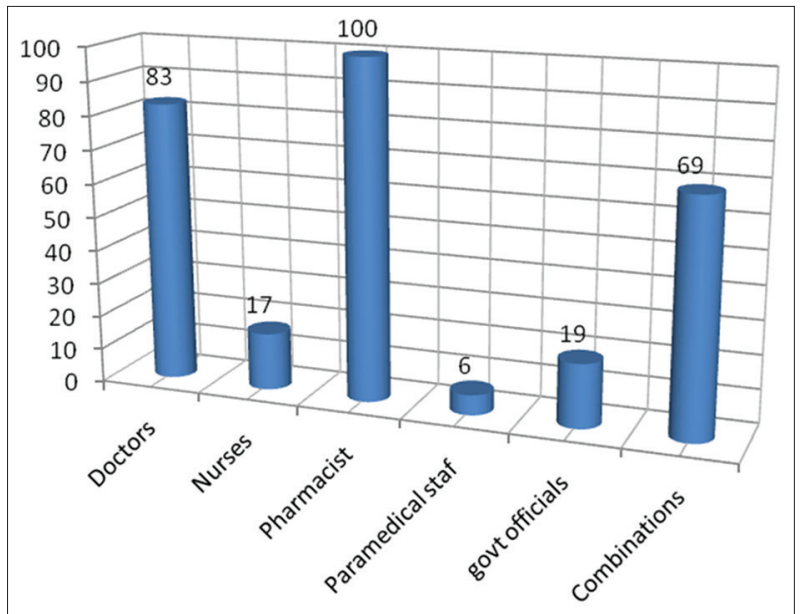

Fig. 5: Who will be appropriate to inform about proper disposal, expressed in number of respondents

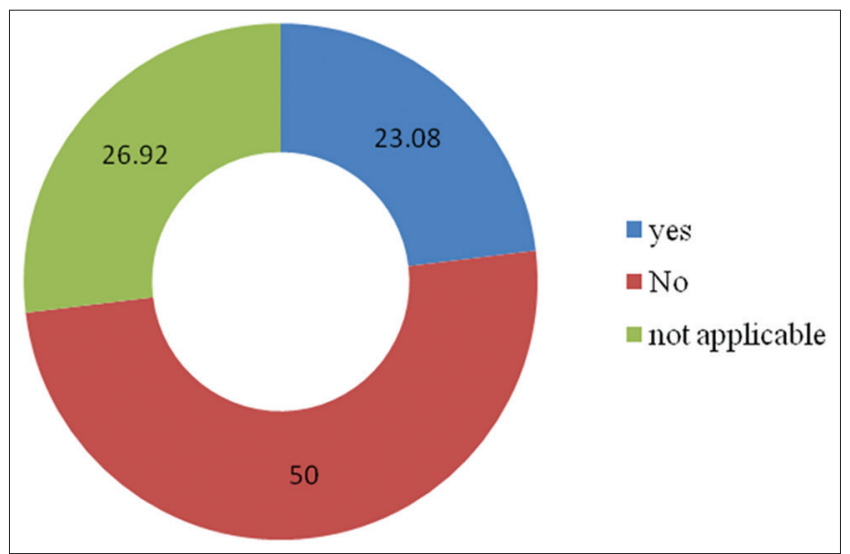

Fig. 6: Have you ever educated your patient about the disposal methods, expressed in percentage $(\%)$

and 3\% of the professionals follow throwing in their household bins and flushing in toilets, whereas in the study [16] conducted by Swaroop et al., $65 \%$ and $9 \%$ of the professionals throw in the garbage and sink or toilets, respectively.

Federal guidelines from the office of national drug control policy advise consumers about proper disposal of prescription drugs. According to the guidelines by the Office of National Drug Control Policy [17], expired drugs should be mixed with undesirable substance such as coffee grounds or kitty litter, and putting them in impermeable, non-descript containers to prevent diversion of drugs, whereas the original containers were thrown in the trash. Flushing prescription drugs down the toilet can be followed only if specific mention is provided on the label. For example, fentanyl, morphine, gatifloxacin, and stavudine should be flushed down instead of thrown in the trash. The above-said precautionary measures can be followed in countries where pharmaceutical take-back programs are in the primitive stage. Otherwise, community take-back programs or solid waste programs are the best option, which allow the public to bring expired drugs to a central location for proper disposal. In our study, 75\% were aware about the consequences of improper disposal. The other (25\%) onefourth of the medical professionals was not aware or believes that there is no harm which was not satisfying or expected from them. In another study conducted among pharmacist, $35 \%$ were aware, and $64 \%$ were not aware about the consequences.

Regarding appropriate person to inform about proper disposal of expired drugs in the present study, 44\% have opted more than one personnel 
that shows professionals from various sectors should equally contribute to curtail this environmental issue. Doctors can educate their patients about the precautionary measures during consultation, whereas nurses and other paramedical staffs can conduct demonstrations or role play to stress on the importance of safe disposal of expired drugs. Along with the prescription drugs, pharmacist can provide pamphlets indicating precautionary measures in their local regional language. Government officials should initiate various community take-back programs and strict regulations should be followed at all levels till proper disposal of expired drug happens.

\section{CONCLUSION}

Knowledge about proper disposal of drugs among medical professionals is still lacking, and discussion on this topic can be given priority in CMEs, conferences, and seminars. As improper disposal of expired drugs causes potentially harmful effects, medical professionals should join hands and coordinate with other professionals to overcome this global issue.

\section{ACKNOWLEDGMENT}

Our sincere thanks to the Management of Tagore Medical College and Hospital, Chennai, for their constant support and encouragement. We extend our thanks to both medical and dental doctors sparing their valuable time in providing the information for the successful completion of the study.

\section{REFERENCES}

1. National Formulary of India. Appendix 7: Disposal of Unused/Expired Pharmaceutical Products. $5^{\text {th }}$ ed. Ghaziabad: Disposal of Unused, Expired Pharmaceutical Products; 2016. p. 756-9.

2. Satoskar RS, Rege NN, Bhandarkar SD. Pharmacology and Pharmacotherapeutics. 22 $2^{\text {nd }}$ ed. Mumbai: Popular Prakashan Private Limited.; 2011.

3. Guidelines for Safe Disposal of Unwanted Pharmaceuticals in and after Emergencies. WHO; 1999. Available from: http://www. who.int/watersanitation health/medicalwaste/unwantpharm.pdf. [Last assessed on 2017 June 20].

4. Aditya S. Safe medication disposal: Need to sensitize undergraduate students. Int J Pharm Life Sci 2013;4(3):2475-80.

5. Altschuler R. Do Medicines Really Expire? Medscape General Medicine; 2003. Available from: http:/www.medscape.com/ viewarticle/460159. [Last accessed on 2017 June 11].

6. Good Practice Guidance 4: Expiry Dates for Medication; 2010. Available from: https://www.scribd.com/document/335531992/04Good-Practice-Guidance-4-Expiry-Dates-for-Medication. [Last accessed on 2017 May 31].

7. Gross JM. Fanconi syndrome (adult type) developing secondary to the ingestion of outdate tetracycline. Ann Intern Med 1963;58:523-8.

8. Frimpter GW, Timpanelli AE, Eisenmenger WJ, Stein HS, Ehrlich LI. Reversible "Faconi syndrome" caused by degraded tetracycline. JAMA 1963;184:111-3.

9. Hemstreet BA. Antimicrobial-associated renal tubular acidosis. Ann Pharmacother 2004;38(6):1031-8.

10. Wegienka LC, Weller JM. Renal tubular acidosis caused by degraded tetracycline. Arch Intern Med 1964;114:232-5.

11. Jawahir S, Aziz NA. Self-medication among adult population in selangor, Malaysia. Int J Pharm Pharm Sci 2017;9(5):268-74

12. Sirisha A, Janardhan M, Sree PK, Rao YV, Raikar SR, Patil S. Knowledge, attitude and practice on safe disposal of medicines among medical and dental undergraduates. J Basic Clin Res 2016;3(1):5-9.

13. Pranav V, Narayanan P, Guddattu V. Self-medication practice among urban slum dwellers in Udupi Taluk, Karnataka, India. Int J Pharm Pharm Sci 2017:9(6):19-23.

14. Radhakrishnan L, Nagarajan P. Pharmacist's opinion and practice towards disposal of unused medications in South India. World J Pharm Sci 2015;3(3):654-57.

15. Saharan V, Pandey M. A study of prevalance of self medication practice among people of Mumbai. Int J Pharm Pharm Sci 2015;7(7):253-6.

16. Swaroop HS, Chakraborty A, Virupakshaiah A. Knowledge, attitude and practice of medical professionals towards the safe disposal of unused medications in South India. World $\mathrm{J}$ Pharm Pharm Sci 2015;4(5):1423-30.

17. Office of National Drug Control Policy. Proper Disposal of Prescription Drugs; 2007. Available from: http://www.whitehousedrugpolicy.gov. [Last accessed on 2017 Jun 02]. 